\title{
Chemical Reduction of Titania Supported Gold by Glycerol
}

\author{
Pandian Lakshmanan, Vadivel Saravanan, Chennan Ramalingan
}

\begin{abstract}
Gold was loaded on $\mathrm{TiO}_{2}$ by deposition precipitation method (DPU). The as prepared DPU samples were reduced in the liquid phase through chemical reduction with pure glycerol. The advantage of this method is that, the formation of small particles (less than $7 \mathrm{~nm}$ ) can be prevented. The chemically reduced $0.93 \%$ Au/TiO $\mathrm{O}_{2}$ sample exhibited an average gold size of $12.6 \pm 0.92 \mathrm{~nm}$ while, the $\mathrm{H}_{2}$-reduced counterpart showed $4.2 \pm 0.25 \mathrm{~nm}$. The efficacy of the size-controlled catalyst was demonstrated in the selective oxidation of $\mathrm{HMF}$. The chemically reduced samples exhibited excellent selective oxidation performance by forming exclusively one product. This study reveals the possibility of controlling the size of metal-oxide supported gold catalysts.
\end{abstract}

Keywords: Gold nanoparticles, Titania, chemical reduction, glycerol, selective oxidation, size-controlled synthesis.

\section{INTRODUCTION}

$\mathrm{T}$ the most interesting transition metal oxide support in heterogeneous catalysis due to its reactivity, eco-friendliness, low cost and abundance [1]. Loading $\mathrm{TiO}_{2}$ with gold nanoparticles leads to many exciting catalytic applications including $\mathrm{CO}$ oxidation in the gas phase [2-4] and photocatalytic activity in the liquid phase [5-8]. Due to the localized surface plasmon resonance (LSPR) the gold nanoparticles help titania to strongly absorb visible light. But, the LSPR properties are influenced strongly by the characteristics of gold nanoparticles such as shape [9], size [10-12] and gold loading [13]. Clearly, these characteristics of gold nanoparticles can be used as tools to tailor the catalytic properties of $\mathrm{Au} / \mathrm{TiO}_{2}$ catalysts. reaction. Supported gold catalysts with small gold size (2-3 $\mathrm{nm}$ ) exhibited the best $\mathrm{CO}$ oxidation activity [2-4]. But small gold particles are not required for all reactions. Particularly, for the base-assisted selective oxidation reactions, medium sized particles $(\sim 8-10 \mathrm{~nm})$ have shown better performance than that of smaller gold particles [14-15]. But in general, the net catalytic activity is obtained as the sum of dispersed atoms, small clusters, nanoparticles of varying sizes. This is the main problem in the activity-size correlation. It would be better to have narrow size distribution and the monodispersity would be the best case which remains only imaginable. In order to control the size of metal oxide-supported gold nanoparticles, two options have been attempted. One is size control through gold loading $[12,13]$.

\footnotetext{
Revised Manuscript Received on December 05, 2019.

Pandian Lakshmanan Indian Institute of Chemical Technology, Hyderabad, India.

Vadivel Saravanan research scholar department of Chemistry, KARE. Minneapolis, Minnesota

Chennan Ramalingan, research scholar department of Chemistry, KARE. Minneapolis, Minnesota
}

However, the gold size requirement depends on the type of

But this can work up to certain limits only and again the histogram looks with broader size distributions, just in different size ranges. In general, the $\mathrm{Au}(\mathrm{III}) / \mathrm{TiO}_{2}$ samples are either calcined or reduced. Note that, thermal reduction under flowing hydrogen always generates only small particles $(\leq 5 \mathrm{~nm})$ even with high gold loadings such as $5 \% \mathrm{Au} / \mathrm{TiO}_{2}$. Therefore, the current challenge is to control the size/ shape of oxide-supported gold nanoparticles. Here, we report the preparation of $\mathrm{Au} / \mathrm{TiO}_{2}$ catalyst without the presence of small gold particles achieved through the techniques of chemical reduction method. In this method, glycerol is used as reducing agent. No other chemicals are needed. The advantages of glycerol include non-toxicity, non-hazardousness, non-volatility, biodegradability that is generated as a byproduct in the manufacture of biodiesel fuel from vegetable oils. One of the attractive physical properties of glycerol is its high boiling point $\left(290^{\circ} \mathrm{C}\right)$. Furthermore, its high viscosity (1.412 Pa.s) [16] can prevent fine particles from settling down. This study demonstrates that, size-controlled synthesis of oxide-supported gold catalysts is possible by chemical reduction method. The results show that, even with low loading like $1 \mathrm{wt} . \% \mathrm{Au}$, it is possible to prevent the formation of nanoparticles below $7 \mathrm{~nm}$, which is very interesting for selective oxidations.

\section{EXPERIMENTAL SECTION}

\section{A. Chemicals and Techniques}

$\mathrm{HAuCl}_{4} .4 \mathrm{H}_{2} \mathrm{O}$ (SHOWA, 99.9\%), glycerol (Aldrich, 99\%), $\mathrm{TiO}_{2}$ (Degussa, $50 \mathrm{~m}^{2} \mathrm{~g}^{-1}$ ), and urea (Aldrich, $98 \%$ ) were used as received. The glassware used in the synthesis was cleaned with aqua-regia and then rinsed with deionized water and dried overnight .prior to use. Chemical analyses were performed by duo inductively coupled plasma atom emission spectroscopy (ICPAES) with Thermo Scientific iCAP 6500 instrument. The Au loadings were expressed as wt $\%$. The TEM study done with a TECNAI G2 microscope. UV-Vis analysis were performed out with SHIMADZU UV-1800 equipment.

\section{B. Preparation of Catalyst}

$\mathrm{TiO}_{2}$ was dispersed in distilled water and the slurry temperature was kept $80{ }^{\circ} \mathrm{C}$. Solution of $\mathrm{HAuCl}_{4} \cdot 4 \mathrm{H}_{2} \mathrm{O}$ was added. It was followed by urea addition. The mixture was heated at $80^{\circ} \mathrm{C} / 12 \mathrm{~h}$. Centrifugation was performed to recover the solid, washed 3 times with water and dried in a desiccators. The aliquots of .dried (as prepared) samples were treated in glycerol at different temperatures to obtain reduced gold catalyst. In a typical process, $150 \mathrm{mg}$ of finely powdered as prepared samples was and mixed with $30 \mathrm{~g}$ of pure glycerol in a closed $50 \mathrm{~mL}$ vial and stirred vigorously. 
The catalyst mixed well with the glycerol due to the presence of residual moisture in the as prepared catalyst and hygroscopic nature of glycerol. The reaction mixture was stirred at $100{ }^{\circ} \mathrm{C}$ in an oil bath for $12 \mathrm{~h}$. The progressive reduction of gold could be followed with changes in color (which is not possible with conventional gas-phase catalyst activation). After stirring for $12 \mathrm{~h}$, the reaction mixture was removed from oil bath, cooled and diluted with excess of water. Centrifugation was performed to recover the catalysts, followed by washing ( 3 times with deionized water) and finally mixed with the reaction mixture immediately. For the purpose of comparison, thermal reduction under flowing $\mathrm{H}_{2}$ was performed (at $300^{\circ} \mathrm{C} / 2 \mathrm{~h}$ ) with the as prepared catalysts.

\section{Chemicals and Techniques}

Aerobic oxidation of 5-Hydroxymethyl-2-furfural (HMF) was performed with supported gold catalysts. In a typical reaction, $0.1 \mathrm{~g} \mathrm{HMF}$ was dissolved in $100 \mathrm{~mL}$ distilled water and transferred into the stainless steel reactor followed by the addition of base $(0.125 \mathrm{mg})$ and catalyst $(150 \mathrm{mg})$. The reactor was closed with screw cap very tightly and 40 bar air pressure was applied. After stirring at $25^{\circ} \mathrm{C}$ for $1 \mathrm{~h}$, the reaction was stopped. The product analysis was done by HPLC [Alltech OA-1000 column $(300 \mathrm{~mm} \times 6.5 \mathrm{~mm})$ with eluent $0.1 \% \mathrm{H}_{3} \mathrm{PO}_{4}$. $0.5 \mathrm{~mL}$ reaction mixture was diluted to a total of $5.0 \mathrm{~mL}$ with eluent. by $\mathrm{UV}(210 \mathrm{~nm})$ and refractive index detectors used to identify products.

\section{RESULTS AND DISCUSSION}

The chemical analyses performed by ICPAES shows that, the gold loading of the catalysts is $0.93 \mathrm{wt} \% \mathrm{Au} / \mathrm{TiO}_{2}$ which is close to the nominal loading of $1 \%$. Fig. 1 shows the TEM image and gold size distribution of $0.93 \% \mathrm{Au} / \mathrm{TiO}_{2}$ sample reduced by chemical reduction with glycerol (CRG) at 100 ${ }^{\circ} \mathrm{C} / 12 \mathrm{~h}$.

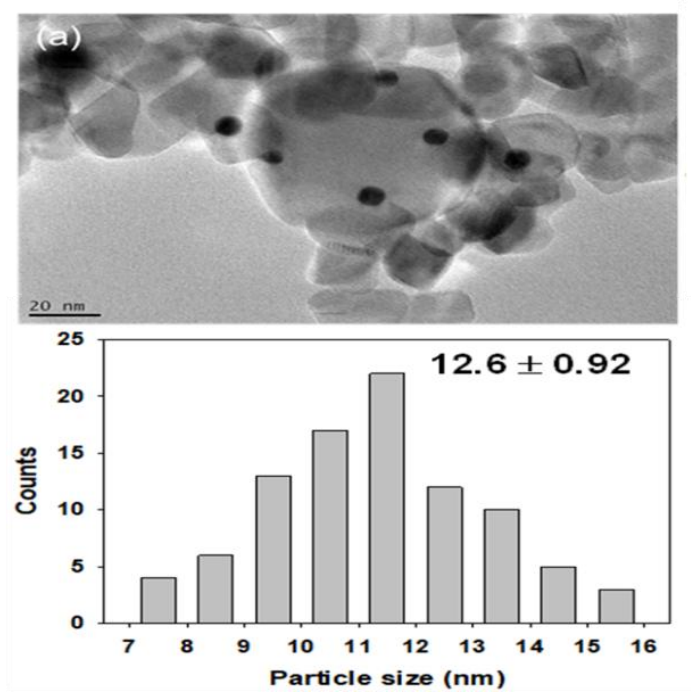

Fig. 1.TEM image and gold size distribution chemically reduced $0.93 \mathrm{Au} / \mathrm{TiO}_{2}$ catalyst.

Note that, the lowest gold size obtained lies above $7 \mathrm{~nm}$, which a remarkable achievement in the size-controlled synthesis of oxide-supported gold nanoparticles. The 0.93 $\mathrm{wt} \% \mathrm{Au} / \mathrm{TiO}_{2}$ exhibits an average size of $12 \pm 0.96 \mathrm{~nm}$. Very large particles above $17 \mathrm{~nm}$ are also clearly absent. Interestingly, the gold loading is not very high (0.93 wt.\% only) but, the average size of gold is above $10 \mathrm{~nm}$, which is the unique advantage of this chemical reduction method.

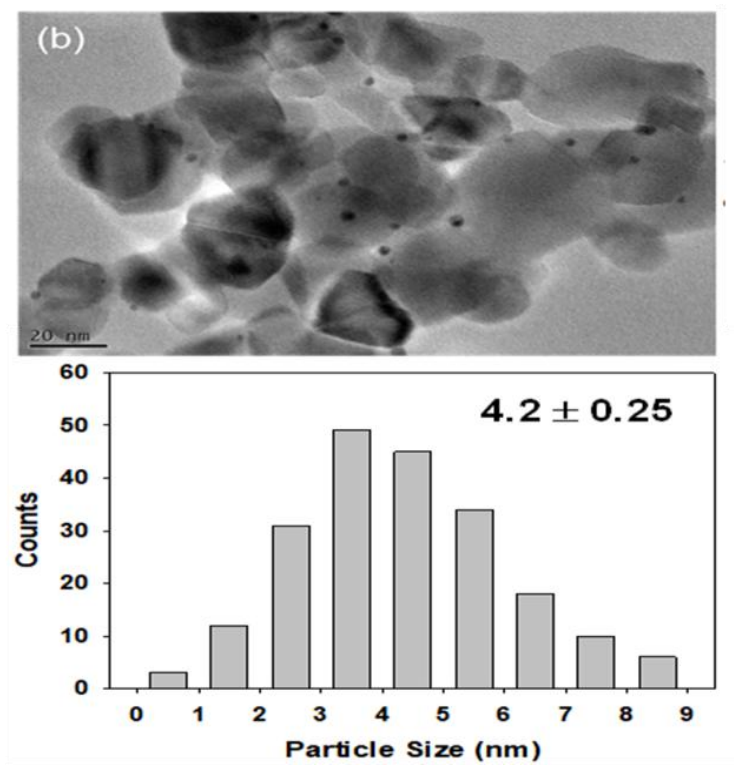

Fig. 2.TEM image and gold size distribution of $0.93 \mathrm{Au} / \mathrm{TiO}_{2}$ catalyst. reduced by flowing $\mathrm{H}_{2}$ at 300 ${ }^{\circ} \mathbf{C} / 2 \mathbf{h}$.

That is, not only larger gold particles can be grown, but also, smaller particles can be effectively avoided. The same sample reduced under flowing $\mathrm{H}_{2}$ (at $300{ }^{\circ} \mathrm{C} / 2 \mathrm{~h}$ ) results into an average size of $4.2 \pm 0.25 \mathrm{~nm}$, which is normal as expected. Compare the Fig. 1 with Fig. 2. The TEM results reveal that, the characteristics of gold particles vary greatly with the applied reduction method.

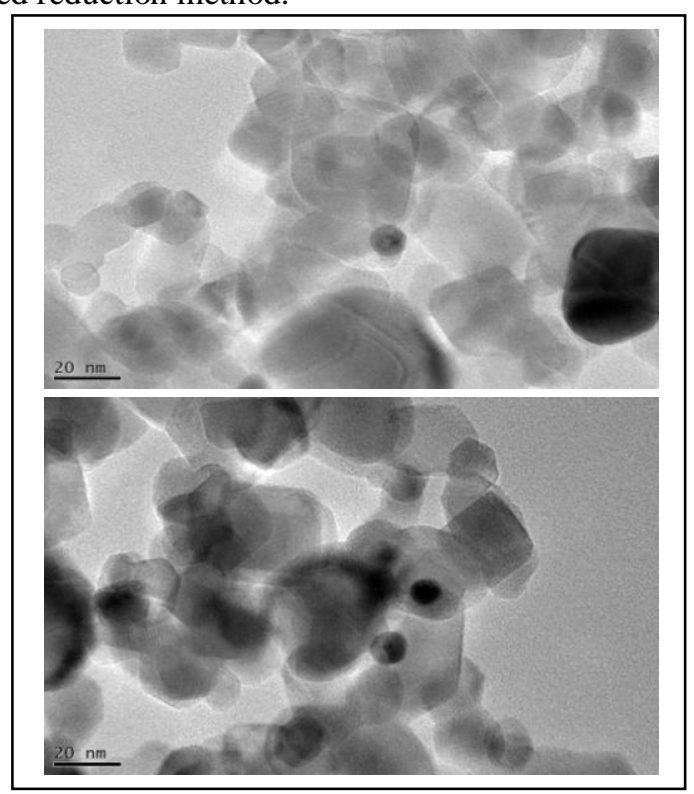

Fig. 3.TEM images of chemically reduced $0.93 \mathrm{Au} / \mathrm{TiO}_{2}$ catalyst.

As could be seen from the Fig.-1, the sample reduced by CRG method produced larger gold particles than that of $\mathrm{H}_{2}$-reduced samples. Note that, the gold size distribution is entirely in different ranges for these samples. 
TEM images of chemically reduced sample were carefully examined and it was found that, the smaller gold particles below $7 \mathrm{~nm}$ were clearly absent (Fig. 3). These results indicate that, the growth of large particles with low gold loading is possible with CRG method, which is not possible with the conventional method of reducing under flowing $\mathrm{H}_{2}$. Furthermore, the present study reveals the efficacy of glycerol as a reducing agent.

It may appear quite different approach. When the as prepared DPU sample was mixed with glycerol, it was observed that, the fine powders mixed very well with glycerol by stirring [Fig. 4]. The driving force for such an observation could be related to the hygroscopic nature of glycerol and the residual moisture present in the as prepared DPU samples. In order to understand the growth of gold nanoparticles during chemical reduction method, sample drawn in between beginning and finished catalyst was examined [Fig. 5]. As could be seen from the figure, first small clusters appear and later, they merge to form larger particles, which is in line with the absence of smaller gold particles.

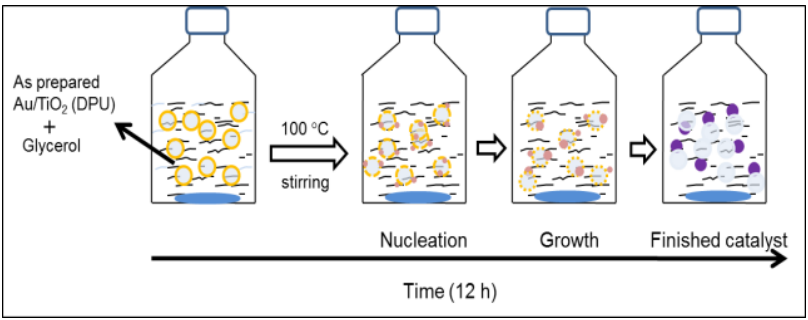

Fig. 4. Chemical reduction of gold over titania.

In fact, glycerol has been used to reduce various metals (but unsupported metals). Glycerol has been used as reducing agent for the ions of silver, gold and nickel. Gold nanoparticles have been obtained by reduction of $\mathrm{HAuCl} 4$ encapsulated with liposome [17]. Gold was reduced in glycerol under both microwave and reflux conditions [18]. Nickel nanoparticles have been prepared in glycerol at 100 ${ }^{\circ} \mathrm{C}$ by using hydrazine hydrate in alkaline medium [19]. Silver ions in silver alkoxide has been reduced by glycerol to form silver nano-particles (D av. < $63 \mathrm{~nm}$ ) at high temperature [20]. Nalawade et al [21] applied pure glycerol to reduce $\mathrm{HAuCl}_{4}$ at room temperature under basic conditions $\left(\mathrm{HAuCl}_{4}: \mathrm{NaOH}\right.$ mole ratio $\left.=1: 5\right]$. Gold size varied from 8 to $50 \mathrm{~nm}$ [21]. Interestingly, the concentration of glycerol played key role in determining the characteristics of resulting nanaoparticles. 20:80 ( $\mathrm{vol} / \mathrm{vol})$ mixture of glycerol and water produced the best results in the absence of stabilizers like PVP [21]. The advantage of the present method is that, it does not require any other reagent than pure glycerol, becoming a green protocol. It should be mentioned here that, in our earlier study, this technique worked at even room temperature with nano ceria support. However, for the $\mathrm{Au} / \mathrm{TiO}_{2}$ samples, it did not work at room temperature.

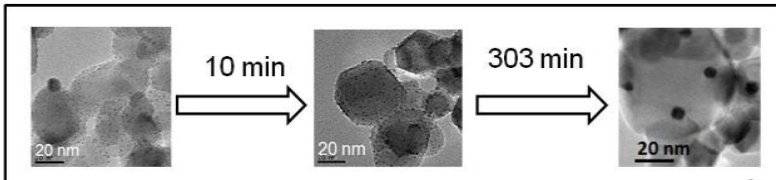

Growth of gold over titania during heating in glycerol at $100^{\circ} \mathrm{C}$

\section{Fig. 5.Time dependant TEM analysis of $0.93 \mathrm{Au} / \mathrm{TiO}_{2}$ catalyst during chemical reduction process.}

The striking advantage of this chemical reduction method was revealed in the catalytic activity tests. Among various supports, gold supported on $\mathrm{TiO}_{2}$ was proved to be effective for HMF oxidation into 2,5-Furandicarboxylic acid (FDCA) [22]. According to Casanova et al [22], HMF oxidation to 5-hydroxymethyl-2-furancarboxylic acid (HMFCA) is a very fast reaction.
A<smiles>O=Cc1ccc(C=O)o1</smiles><smiles>CCCC</smiles>
$\mathrm{HO}^{\mathrm{CHO}}$<smiles>CC(C)=CC(=O)c1ccc(C(=O)O)o1</smiles>
D
B<smiles>O=Cc1ccc(C(=O)O)o1</smiles><smiles>CCCCCCCCCCCCC(=O)O</smiles>

C

\section{Scheme. 1: Various oxidation products possible from HMF}

The conversion of HMF and the product distribution depends strongly on the reaction conditions. The different types of oxidation products from HMF are depicted in the Scheme-1. According to Casanova et al [22] and Pasini et al [23], initially HMF is rapidly converted into HMFCA and it is a primary and unstable product that is gradually converted into FDCA, which appeared as a secondary and stable product. It has been pointed out that, FDCA was practically not formed before all HMF was converted into HMFCA, indicating the slower reactivity of HMFCA compared with HMF. Higher reaction temperature and higher base concentration boost the undesirable rapid degradation of HMF into by products [24]. On the other hand, at lower temperatures, HMFCA was the major product at complete conversion of HMF (Scheme-2).

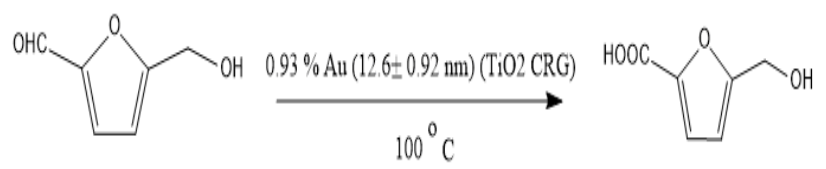

Scheme. 2 : Selective oxidation of HMF over size-selective $\mathrm{Au} / \mathrm{TiO}_{2}$ catalyst.

At $60{ }^{\circ} \mathrm{C}, 1 \% \mathrm{Au}(5.2 \mathrm{~nm}) / \mathrm{TiO}_{2}$ catalyst produced $20 \%$ and $80 \%$ yields of FDCA and HMFCA (Reaction conditions: 240 min, 10 bar of oxygen pressure, HMF : metal loading : $\mathrm{NaOH}$ molar ratio $1: 0.01: 4$ ) respectively [23]. The yield of FDCA was $>99 \%$ with the $\mathrm{Au} / \mathrm{TiO}_{2}$ in an another study reported by Casanova et al [22] (Reaction conditions: 


\section{Chemical Reduction of Titania Supported Gold by Glycerol}

$\mathrm{HMF}(3 \mathrm{mmol})+\mathrm{NaOH}(12 \mathrm{mmol})$ in $20 \mathrm{~mL} \mathrm{H}_{2} \mathrm{O}$, the reaction mixture was loaded into an autoclave bubbling air flow $0.5 \mathrm{~mL} \mathrm{~s}^{-1}$ at $\left.10 \mathrm{bar}\right) .1 .6 \% \mathrm{Au}(2.6 \mathrm{~nm}) / \mathrm{TiO}_{2}$ [25] exhibited full conversion of $\mathrm{HMF}$ at $22{ }^{\circ} \mathrm{C}$ with $8 \%$ and $92 \%$ selectivities to FDCA and HMFCA respectively $(0.15 \mathrm{M}$ $\mathrm{HMF}$ solution in $0.3 \mathrm{M} \mathrm{NaOH}$; metal : $\mathrm{HMF}=6.67 \times 10^{-3}$ $\mathrm{mol} / \mathrm{mol}, \mathrm{T}=22{ }^{\circ} \mathrm{C}, \mathrm{P}=690 \mathrm{kPa} \mathrm{O}_{2}$. Reaction time $=6 \mathrm{~h}$ ).

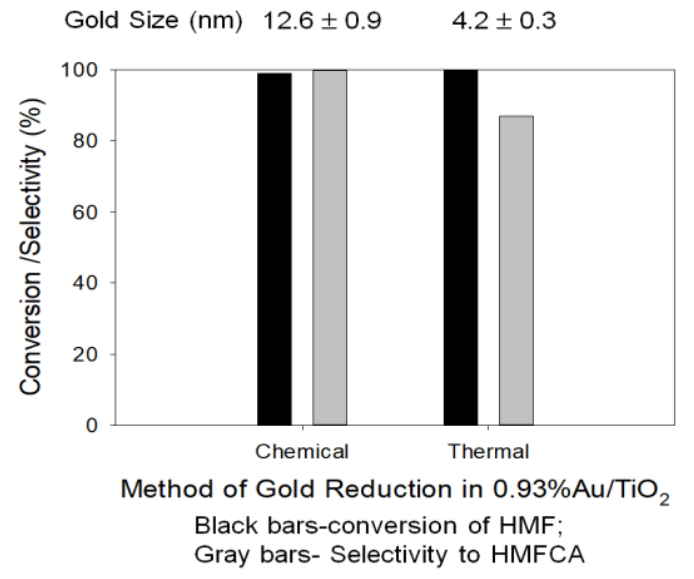

\section{Fig. 6.Conversion and selectivity of differently reduced gold catalysts towards oxidation of HMF.}

Selective oxidation reaction of HMF was studied with chemically reduced samples and compared with that of $\mathrm{H}_{2}$-reduced samples. Figure- 6 shows the comparative results of selective oxidation of HMF under mild conditions. The $0.93 \% \mathrm{Au} / \mathrm{TiO}_{2}$ sample reduced by $\mathrm{H}_{2}$ shows that, at full HMF conversion, the main product is 5-hydroxymethyl-2-furfural (HMFCA) along with FDCA as a minor product. This result is in accordance with the previous reports $(23,25]$. On the other hand, the chemically reduced counterpart showed that, HMFCA was the only product and the FDCA formation is suppressed to trace (at 99\% HMF conversion). This can be attributed to the relatively larger size of gold particles in the case of chemically reduced samples which catalyzed very mild oxidation. The suppressing of FDCA formation is in accordance with the absence of small gold particles $(<7 \mathrm{~nm})$ (Fig. 3) and in agreement with the aforementioned literature reports $[14,15,26,27,23]$. In order to ascertain the catalytic performance of $0.93 \% \mathrm{Au} / \mathrm{TiO}_{2}$ sample reduced by CRG method, recycling tests were performed. The used sample was washed with aq. $\mathrm{NaOH}(50 \mathrm{~mL}$ of $0.3125 \mathrm{M} \mathrm{NaOH})$ once and distilled water ( 3 times) and immediately transferred into the fresh reaction mixture.

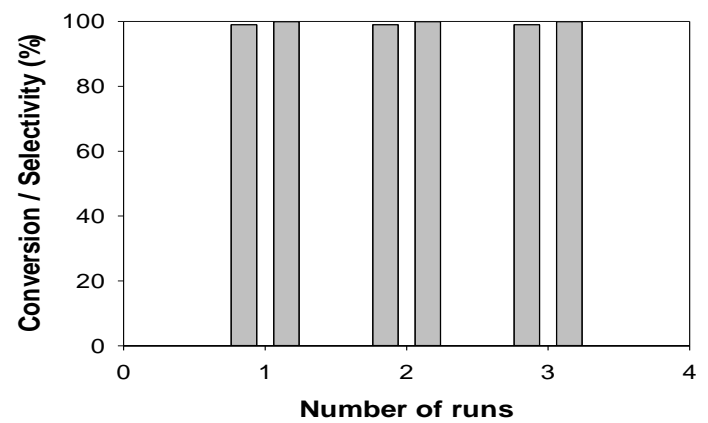

Fig. 7. Results of reproducibility tests of $\mathrm{HMF}$ selective oxidation with $0.93 \% \mathrm{Au}(12.6 \pm 0.9 \mathrm{~nm}) / \mathrm{TiO}_{2}$ catalyst.
Figure 7 shows the results obtained from the re-cycling tests. The conversion of HMF did not decrease and the product distribution is the same, showing the effectiveness of the chemical reduction method to prepare $\mathrm{Au} / \mathrm{TiO} \mathrm{O}_{2}$ catalysts. A catalytic run was conducted in the absence of the catalyst. Without catalyst, only very low conversion of HMF occurred and only the Cannizzaro products were obtained.

\section{Conclusions}

The process of chemical reduction with glycerol has been demonstrated with the as prepared $\mathrm{Au} / \mathrm{TiO}_{2}$ (DPU) samples. Glycerol effectively reduces titania supported gold phase at $100{ }^{\circ} \mathrm{C}$. Smaller gold particles could be successfully prevented, which is a remarkable advantage for the selective oxidation catalysis. Compared with the conventional thermal reduction under flowing hydrogen at $300{ }^{\circ} \mathrm{C}$, relatively larger gold nanoparticles can be prepared by CRG method at 100 ${ }^{\circ} \mathrm{C}$. The catalytic efficiency of chemically reduced $\mathrm{Au} / \mathrm{TiO}_{2}$ samples has been examined in the selective oxidation of 5-hydroxymethyl-2-furfural under very mild conditions. The catalytic results revealed the advantage that, $\mathrm{Au} / \mathrm{TiO}_{2}$ samples $(\mathrm{CRG})$ exhibited very mild and controlled oxidation capacity than that of $\mathrm{Au} / \mathrm{TiO}_{2}\left(\mathrm{H}_{2} / 300{ }^{\circ} \mathrm{C}\right)$ due to larger size. Only product obtained was HMFCA. This study throws light on the size-controlled synthesis of metal oxide-supported gold catalysts which is crucial for selective oxidations.

\section{ACKNOLEDGEMENTS}

This work was financially supported by the Kalasalingam Academy of Research and Education (KARE).

\section{REFERENCES}

1. X. Chen and S. Mao, "S. Titanium Dioxide Nanomaterials: Synthesis, Properties, Modifications, and Applications". 2007. Chem. Rev. 107, pp 2891-2959.

2. F. Cosandey and T. E. Madey, 2001 Surf. Rev. Lett, 8, pp 73-83)

3. G. R. Bamwenda, S. Tsubota, T. Nakamura and M. Haruta, 1997. Catal.Lett. 44, pp 83-88.

4. M. Valden, X. Lai and D. W. Goodman, 1998, Science., 281, pp 1647-1650.

5. Zhang, D. Q. et al. Au Nanoparticles Enhanced Rutile $\mathrm{TiO}_{2}$ Nanorod Bundles with High Visible-Light Photocatalytic Performance for NO Oxidation. 2014, Appl. Catal. B-Environ. 147, pp 610-616.

6. Nalbandian, M. J. et al. Tailored Synthesis of Photoactive $\mathrm{TiO}_{2}$ Nanofibers and $\mathrm{Au} / \mathrm{TiO}_{2}$ Nanofiber Composites: Structure and Reactivity Optimization for Water Treatment Applications. 2015, Environ. Sci. Technol. 49, pp 1654-1663.

7. M. McEntee, A. Stevanovic, W. J. Tang, M. Neurock, and J. T. Yates, Electric Field Changes on Au Nanoparticles on Semiconductor Supports-the Molecular Voltmeter and Other Methods to Observe Adsorbate-Induced Charge-Transfer Effects in Au/TiO ${ }_{2}$ Nanocatalysts”. 2015, J. Am. Chem. Soc. 137, pp1972-1982.

8. Tsukamoto, D. et al. "Gold Nanoparticles Located at the Interface of Anatase/Rutile $\mathrm{TiO}_{2}$ Particles as Active Plasmonic Photocatalysts for Aerobic Oxidation”. 2012, J. Am. Chem. Soc. 134, pp 6309-6315.

9. Ma, L. et al., "Synthesis of Dumbbell-Like Gold-Metal Sulfide Core-Shell Nanorods with Largely Enhanced Transverse Plasmon Resonance in Visible Region and Efficiently Improved Photocatalytic Activity', 2015, Adv. Funct. Mater. 25, pp898-904. 
10. Zielinska-Jurek, A. et al., "Preparation and Characterization of Monometallic ( $\mathrm{Au})$ and Bimetallic ( $\mathrm{Ag} / \mathrm{Au})$ Modified-Titania Photocatalysts Activated by Visible Light", 2011, Appl. Catal. B-Environ.101, pp504-514.

11. K. Kimura, S. Naya, and Y. Jin-nouchi, $\mathrm{TiO}_{2}$ "Crystal Form-Dependence of the $\mathrm{Au} / \mathrm{TiO}_{2}$ Plasmon Photocatalyst's Activity”. 2012, J. Phys. Chem. C 116, pp 7111-7117.

12. M. Murdoch, G. I. N. Waterhouse and M. A. Nadeem, "The Effect of Gold Loading and Particle Size on Photocatalytic Hydrogen

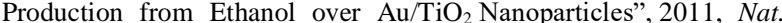
Chem.3, pp 489-492.

13. A. Tanaka, S.Sakaguchi, and K. Hashimoto, "Preparation of $\mathrm{Au} / \mathrm{TiO}_{2}$ with Metal Cocatalysts Exhibiting Strong Surface Plasmon Resonance Effective for Photo-induced Hydrogen Formation under Irradiation of Visible Light", 2012, ACS Catal. 3, pp79-85.

14. N. Dimitratos, J. A. Lopez-Sanchez, D. Lennon, F. Porta, L. Prati and A. Villa, Catal. Lett., 2006, 108, pp147-153.

15. P. Haider, B. Kimmerle, F. Krumeich, W. Kleist, J.D. Grunwaldt and A. Baiker, Catal. Lett., 2008, 125, pp169-176

16. Segur, J. B.; Oberstar, H. E. 1951, Viscosity of Glycerol and Its Aqueous Solutions". Industrial \& Engineering Chemistry. 43 (9): pp2117-2120.

17. R. Genc, G. Clergeaud, M. Ortiz and C. K. O'Sullivan, "Green Synthesis of Gold Nanoparticles Using Glycerol Incorporated Nanosized Liposomes," Langmuir, Vol. 27, No. 17, 2011, pp. 10894-10900.

18. N. Grace and K. Pandian, "One Pot Synthesis of Polymer Protected Gold Nanoparticles and Nanoprisms in Glyc-erol," 2006, Colloids and Surfaces A: Physicochemical and Engineering Aspects, 290 pp138-142.

19. K. Singh, K. H. Kate1, V. V. S. Chilukuri and P. K. Khanna, "Glycero Mediated Low Temperature Synthesis of Nickel Nanoparticles by Solution Reduction Method, 2011, J. Nanosci. Nanotechnol., Vol. 11, No. 6, , pp. 5131-5136

20. E. Nisaratanaporn and K. Wongsuwan, "Preparation of Ultrafine Silver Powder Using Glycerol as Reducing Agent," 2008, J. Metals, Materials and Minerals, Vol. 18, No. 2, pp. 1-5.

21. Pradnya Nalawade, Tulsi Mukherjee, Sudhir Kapoor, 2013, Advances in Nanoparticles, 2, pp78-86.

22. S. Casanova, S. Iborra, A. Corma, Chem Sus Chem., 2009, 2, pp1138-1144.

23. Pasini, M. Piccinini, M. Blosi, R. Bonelli, S. Albonetti, N. Dimitratos, J. A. Lopez- Sanchez, M. Sankar, Q. He, C.J. Kiely, G. J. Hutchings, F. Cavani. Green Chem., 2011, 13, pp2091-2099.

24. C. A. Antonyraj, N. T .T. Huynh, S. K. Park, S. Shin, Y. J. Kim, S. Kim, K. Y. Lee, J. K. Cho, Appl. Catal. A., 2017, 547, pp230-236.

25. S. E. Davis, L. R. Houk, E. C. Tamargo, A.K. Datye, R. J. Davis, 2011, Catal. Today. 160 pp55-60.

26. Y.R. Leshkov, C. J. Barret, Z.Y. Liu, J. A. Dumesic, Nature., 2007 447, pp 982-985.

27. A. Corma, S. Iborra, A. Velty, Chem. Rev., 2007, 107, pp2411-2502.

\section{AUTHORS PROFILE}

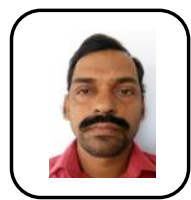

Pandian Lakshmanan completed his doctoral work in the Indian Institute of Chemical Technology, Hyderabad, India. He did postdoctoral work in France and South Korea. At present he is working in the field of heterogeneous catalysis.

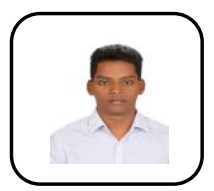

Vadivel Saravanan is currently full-time research scholar in the field of organic chemistry at the department of Chemistry, KARE.

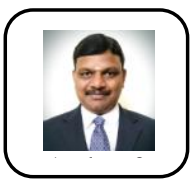

Chennan Ramalingan profile which contains thei education details, their publications, research work, membership, achievements, with photo that will be maximum 200-400 words. 